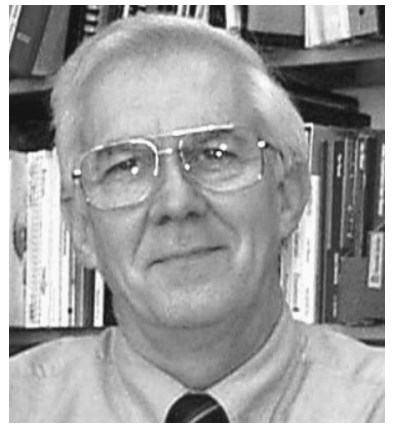

\section{After the Vote}

Almost two years to the day after the first meeting on OSA-SPIE unification took place, the proposal was rejected by OSA members and narrowly approved by SPIE members. Both memberships returned nearly identical results, with $51 \%$ of the voting SPIE members and $49 \%$ of the voting OSA members supporting the merger. Although it passed on the SPIE vote, though just barely, the merger will not take place because of the negative OSA vote. Even had OSA passed the measure with the same approval ratio as SPIE, the merger would have been defeated because OSA by-laws required a supermajority (two-thirds) approval for unification to go forward. So, in one way, the vote was very close and, in another way, it failed by a big margin.

I have since spoken with a number of members and those in the SPIE leadership about the vote. Everyone wants to speculate on the outcome of the vote and tries to derive meaning from the statistics. Many have remarked on the large voting participation by the OSA members $(53 \%)$ and compared it to the SPIE participation (40\%). Although the ballot campaigns were carried out in essentially the same manner by both societies, OSA embarked on a phone campaign when a certain fraction of the ballots were not returned. The SPIE staff designed a package that got a $40 \%$ response with a mail reminder. When you consider that the usual return at SPIE for the annual ballot is around $14 \%$, it is clear that member participation was far greater than usual, and the members and staff are to be congratulated for their effort. Clearly this was an issue of significant interest and importance.

Most were surprised that the OSA vote in favor of the merger was not at least 50\%. I wasn't. As an OSA member, I received the ballot, which included not only the question on the merger, but also selection of OSA leadership positions. If you read the booklet that accompanied the ballot, you found that all of the candidates for Vice President and Director were either neutral or opposed to the merger. Then at the end of the ballot there was the merger proposition. What surprises me is that nearly $50 \%$ of OSA members, having run a gantlet of candidates of which not a single one spoke in favor of the merger, still voted for it.
On the SPIE side, my surprise came from how narrow the margin was. Most of those I had spoken with prior to the vote had expressed a "get on with it" attitude. But then, my sample was based on those I ran into in the course of doing research and working on other projects. One explanation may be that engineers are, by the very nature of what they do, very conservative and didn't want to spoil what they perceive as a "'good thing.' I am sure that, over time, we will get a better read on this. The analysis of this effort should continue so that the SPIE leadership and staff understand the rationale both for and against the vote to merge.

To me the one sad note to the conclusion of this twoyear drama was the response of OSA leadership. The messages by the present and future OSA presidents neglected to acknowledge the considerable efforts, support, and good will on both sides built up by the process. There was no mention of future cooperation with SPIE in their published statements.

So where do we go from here? That was one of the questions that the SPIE Board addressed at its fall meeting in Bellingham a few weeks ago. Return to the status quo ante is not possible. Even as we planned and organized the world was changing.

The strength of SPIE has been its ability to adjust to current conditions. In the midst of all the unification planning and organizing, and administration of the vote, the SPIE Board and staff remained committed to creating a strong strategic plan, whatever the merger outcome. So the Strategic Planning Committee and the staff proceeded full bore during the summer to assemble a comprehensive plan for the next three years. The Board of Directors approved this plan at its fall meeting, and the members of SPIE can be assured that a forward-looking blueprint for the future is in place.

One of the primary reasons for merging the societies was to reduce the competition for the time and loyalty of members in the optics community. Given that no merger will take place, the Society will vigorously seek out new members and serve the needs of our current members. The competitive edge that some members feared would be lost by a merger will certainly be present. The programs to serve the members of SPIE are in place and continually being improved. This was evident during the Board's visit to SPIE headquarters in October. 
As for relations between SPIE and OSA, SPIE President Paul Schenker stated it concisely: "I feel that the best initiative at this point is creative OSA-SPIE cooperation, in tangible projects. I would hope we all retain the sense of commitment and spiritual partnership among both the memberships and staffs that grew significantly during the merger deliberations." I agree that we should continue to cooperate where it is possible and sensible to do so, but not at the expense of the interests of SPIE members. With the appointment of Dr. Eugene Arthurs as the new Executive Director of SPIE, the Society is in a good position to take on the challenges of the next millennium.

Well, I've got another role to play. Come January 1 I will succeed Paul Schenker as SPIE President. Between the resignation of Jim Pearson, the successful search for a new Executive Director, and the activity leading up to the vote on unification, Paul has had an eventful tenure. He has handled it with a great deal of grace and good humor, providing direction and stability during some pretty bumpy times. I hope I do as well as Paul, but I'd like it to be a little quieter during my year in the position.

During my one-year term as SPIE President, it is appropriate that I relinquish the editorship of Optical Engineering. By appointment of the Board of Directors, Roger Lessard of Laval University has agreed to serve as Editor for the year 2000. As one of the members of the Board of Editors, Roger has an intimate knowledge of journal operations and standards. With the assistance of our very capable staff, I leave the journal in good hands.

I hope to get to a fair number of SPIE conferences beyond Photonics West and the Annual Meeting this year and to visit a number of SPIE chapters. I want to talk to members about your perception of the vote just concluded, to understand your concerns about the Society, and to listen to your suggestions for improving SPIE. If we don't happen to meet, see ya on this page in 2001!

Donald C. O'Shea Editor

\section{Optical Engineering Editorial Schedule}

\begin{abstract}
Manuscript submissions for the following special sections should be sent to the appropriate Guest Editor listed below.
\end{abstract}

January 2000

Optical Methods for Shape Measurement

\section{March 2000 \\ Information Optics Using Polymeric Materials}

May 2000

Target Recognition Techniques

July 2000

Pushing the Envelope in Optical Design Software

\section{November 2000}

\section{Machine Vision}

Bruce Batchelor

Cardiff University

Dept. of Computer Science

5 The Parade

Cardiff, CF24 3XF, Wales

United Kingdom

+44(0) $1222874390 \bullet+44(0) 1222874598$ FAX

E-mail: bruce.batchelor@cs.cf.ac.uk

Paul Whelan

Dublin City University

The School of Electronic Engineering

Dublin 9 Ireland

$0035317045489 \bullet 0035317045508$ FAX

E-mail: whelanp@eong.dcu.ic

Prospective authors are invited to submit manuscripts that will emphasize both theoretical research results and practical engineering experience in all areas of machine vision, including but not restricted to the following topics: image acquisition techniques; sensors; algorithmic/heuristic methods; hardware, software, and hybrid systems; systems issues; and practical applications.

Manuscripts due March 1, 2000

\section{January 2001}

\section{Distance and Displacement Measurements by Laser} Techniques

Thierry Bosch

Ecole des Mines de Nantes

Department of Automatic Control and Production Systems

4, rue Alfred Kastler B.P. 20722

44307 Nantes cedex 3 France

$33251858307 \cdot 33251858349$ FAX

E-mail: thierry.bosch@emn.fr

Silvano Donati

Dipartimento de Elettronica

Università di Pavia

via Abbiategrasso 209

I-27100 Pavia Italy

$390382505204 \cdot 390382422583$ FAX

E-mail: donati@ipvsm6.unipv.it

Absolute and relative distance measurement devices are at an important evolutionary stage in industrial countries in terms of applications such as nondestructive testing, reverse engineering, predictive maintenance, and virtual reality. They have the potential to improve the productivity of firms or the quality of manufactured products. In particular, laser distance/ displacement measurements of rough targets are of great interest for many industrial applications. This special section is intended to focus on laser range finding techniques, displacement measurements, and related applications to optical inspection, quality control, intelligent transportation systems, profile measurements, level control, laser-based 3-D vision, proximity sensors, and vibration measurements.

Manuscripts due March 1, 2000 